DOI: 10.20472/IAC.2019.048.052

\author{
JITPANAT SUWANTHEP \\ Suranaree University of Technology, Thailand
}

FANGFANG WANG

Suranaree University of Technology, Thailand

\title{
THE MATERIAL DEVELOPMENT OF EFL VOCABULARY LEARNING VIA CONSTRUCTIVISM-BASED MOBILE APPLICATION
}

\begin{abstract}
:
The study aims at developing EFL vocabulary learning mobile application to enhance students' vocabulary knowledge and retention. The researcher attempted to develop the mobile application based on constructivism theory to learn vocabulary. The application consists 3 parts: Preview, Review 1 and Review 2. The participants were 20 second-year students at Suranaree University of Technology, in Thailand. The application is developed based on Cordova hybrid apps framework and standard web technologies (HTML5, JavaScript and CSS). The vocabulary pretests, post-tests and delayed post-tests, student questionnaires and interviews are employed to collect data. Based on the case study, the results show the constructivism-based vocabulary learning mobile application has positive effects on improving students' vocabulary in terms of vocabulary knowledge and retention; and students express positive opinions towards the implementation of the mobile application. The study concludes with the positive outcomes in further develop the learning application for EFL vocabulary learning.
\end{abstract}

\section{Keywords:}

MALL, constructivism, EFL vocabulary learning

JEL Classification: 129 


\section{Introduction}

With the rapid development of the information and communication technologies, the importance given to foreign language has led innovations in language teaching and learning. Effective teaching approaches have been sought for employing information technologies in foreign language courses. Vocabulary learning and teaching is very important as an essential part of foreign language learning. However, as reported by many researchers (Sawangwaroros, 1984; Ward, 2000; Sukkrong, 2010, Nirattisai \& Chiramanee, 2014), insufficient vocabulary is the major problem among Thai learners which causes them difficulties in reading, listening, speaking, and writing skills. The failure of acquiring vocabulary knowledge is largely related to ineffective vocabulary teaching methods in Thailand, limited time to learn the target words during class, and few opportunities to expose the language outside the classroom. Hence, exploring good methods to develop learners' vocabulary knowledge beyond classroom is important for their successful language acquisition.

Widespread use of mobile and wireless devices in education has drawn a majority of researchers' attention. Mobile Assisted Language Learning is "any type of language learning that takes place with the help of portable devices" (Rahimi \& Miri, 2014, p. 1471). Moreover, research on using mobile phones in education shows that learners consider the mobile phone provided useful learning platform which can provide multimedia contexts, comprehensible input; and immediate and facilitative feedback. Learning with the mobile phone can increase students' personal interest; provide students and help students learn language better (Squire \& Dikkers, 2012). Empirical studies also show that MALL has positive effects on EFL vocabulary learning. Furthermore, large numbers of learners delivered positive attitudes towards using the mobile application to learn language due to its availability, accessibility and convenience (Steel, 2012).

EFL learners acquire English vocabulary via mobile phones was empirically investigated by Thornton \& Houser, 2005, Chen et al (2008), Başoğlu and Akdemir (2010), Taki and Khazaie (2011), Alemi et al (2012) and Hayati, Jalilifar, and Mashhadi (2013). Their studies showed that the mobile phones improved EFL vocabulary learning, however, all their experimental designs were provided target word meaning directly rather than learners constructed it by themselves. Learners learn and remember the words through repetition and frequently doing exercises. This learning method based on behaviorism is boring which has limited advocates for vocabulary learning; therefore, students forget the words they have learned quickly and cannot store the new words in long-term retention (Boonkongsaen, 2013). On the contrary, constructivism emphasizes the importance of what the learner to any learning situation as an active meaning-maker (Lin, 2015). Furthermore, learners learned vocabulary based on constructivism may have deeper conceptual understandings of vocabulary, which facilitates to better transfer vocabulary knowledge to authentic contexts. Also, many researchers reported that vocabulary learning based on constructivism theory can effectively improve learners' vocabulary learning achievements. Nevertheless, presently, there are a limited number of research studies concerning the application of MALL in the Thai context, especially using MALL and constructivism in teaching vocabulary. To fill this gap, the researcher attempts to 
develop and employ a mobile application based on constructivism to enhance university students' English vocabulary learning in Thai contexts. Hopefully, it may yield useful information for popularizing integrating MALL and constructivism theory to improve learners' vocabulary learning in Thailand.

\section{Research questions}

Based on the purposes of the study, this study is driven by the following research questions:

1) What are the effects of using the constructivism-based vocabulary learning mobile application on EFL vocabulary learning achievement?

2) What are the students' opinions towards using the constructivism-based vocabulary learning mobile application to enhance EFL vocabulary learning?

\section{The constructivism-based vocabulary learning mobile application}

\section{A. The origin of vocabularies}

There are a total of 180 English words in 15 chapters of the textbook of English III (Read this! 2). Read this! 2 is a textbook aiming to improve students' reading comprehension skills and critical thinking skills; meanwhile, it also aims to develop students' vocabulary knowledge of the academic words in each chapter (Mackey \& Savage, 2010). It contains 12 target words in each chapter. The curriculum contains 12 chapters of the textbook.

\section{B. The design of the vocabulary learning mobile application}

The mobile application is developed by the researcher in the current study. The application is developed based on Cordova hybrid apps framework, which can run on different mobile operating systems such as Android and IOS devices. The application contains three parts in each unit: Preview, Review 1 and Review 2. These words were programmed into a PC application with six features; namely: pronunciation, sound, related picture, example sentence, Thai meaning and English definitions in the preview part. Next, the researcher used HTML 5 programming language and Cordova hybrid apps framework to develop the mobile application for Android and IOS. For students who use Android system, they can enter the website www.e3and.ml to download the application. For IOS, students should visit the website www.iosenglish.ml to install the application (The researcher used enterprise certificate to distribute the application). It had been beta-tested among Thai classmates before it was installed into smartphones of the participants.

\section{Functions of the vocabulary learning mobile application}

The constructivism-based mobile application has the following three functions. The details are shown in following parts. 

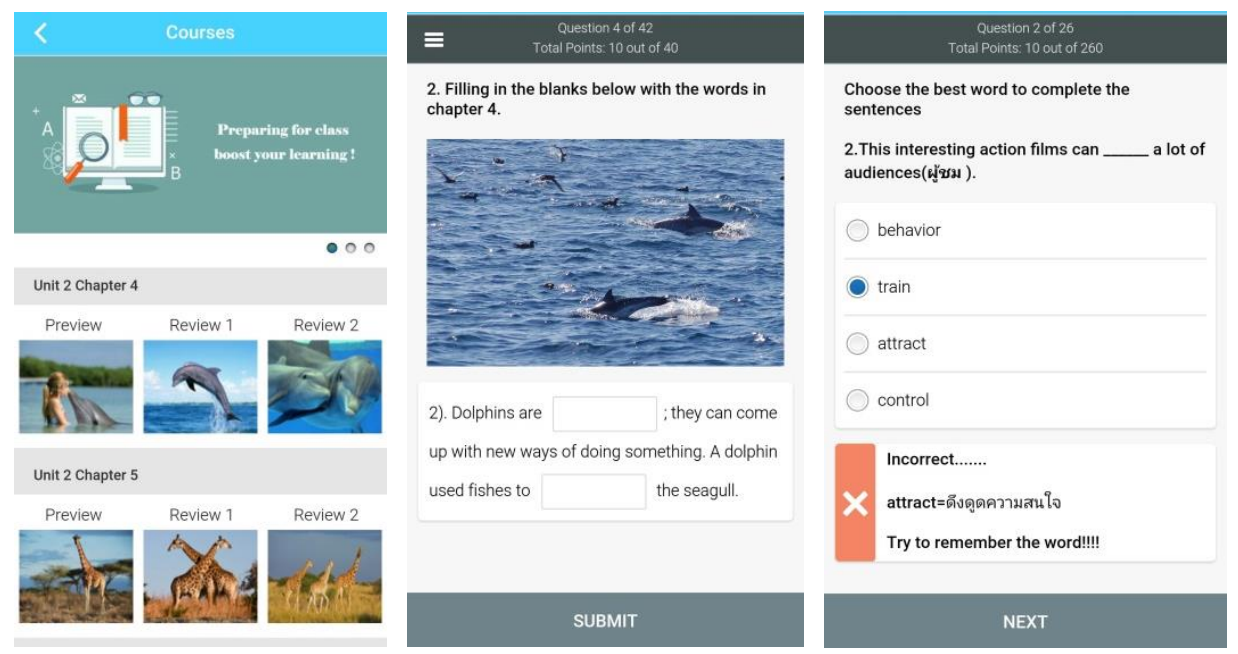

Figure 1: The details of the constructivism-based mobile application

Preview part: learners can learn the target words before class. They should construct the word meaning through their prior knowledge and multiple contexts rather than memorize the word meaning directly. The related pictures, comprehensible contexts and sounds are provided by the application which scaffold learners to build the word knowledge. Then, learners will receive the immediate feedback to reflect on their word construction. The matching exercises and multiple choices are provided after they learn all of the target words of each chapter in order to make them understand and remember the words better.

Review 1: learners need to review the target words via the mobile application after they learn the words in class. Words are reinforced for learners' vocabulary use with 3 exercises that are matching the words with English definitions or Thai meaning, filling in the gap with the given letters of words and choosing the correct answer from the following choices. The immediate feedback helps them reflect and enhance their vocabulary knowledge. Review 1 help the students recognize the word and use the word in new contexts.

Review 2: The mobile application provides Review 2 part for learners to store the words in long retention after class. It is designed based on spaced revision and the vocabulary instruction schedule in the Daloğlu et al study (2009) that learners should review all of the vocabulary items a minimum of three times. The time of each revision was decided on vocabulary retention the fact that vocabulary should be review 1-10 days after learning the words. Therefore, the first practice is carried out the day after in-class exposition of words, the second revision was one week after that, the third one was two weeks after the first time, and the last one appeared three weeks after the third one (Daloğlu et al., 2009).

\section{Research methodology}

\section{A. Subjects}

Twenty second-year students were selected from English III at Suranaree University of Technology to participate in the study. They were selected according to convenience and availability. All of them take a vocabulary pretest to examine their vocabulary proficiency. The 20 participants were divided into a control group and an experimental group based on the 
pretest result. Six of them in the experimental group participated in the interviews.

\section{B. Treatments}

The case study conducted in August, 2015. Firstly, the researcher installed the constructivism-based vocabulary learning mobile application to 10 participants' smartphones in the experimental group and taught them how to use it. Then, the participants in the experimental group should preview the target words in Chapter 4 through learning the preview part in the mobile application. On the contrary, the participants in the control group preview the target words through finding the target words' English definition and Thai meaning by searching for the dictionaries based on the target word list provided by the researcher. During the class, both two groups receive the same vocabulary instruction. After class, the researcher uploaded the Review 1 and Review 2 parts and the experimental group students were required to complete the Review 1 part after they learned Chapter 4 via the application and completed the Review 2 part one week later. The participants in the control group were asked to review and memorize the target words through the word list which was provided by the researcher. Ten days later, all of the participants were required to take the vocabulary post-test. One week after they took the post-test, all of them were asked to take the vocabulary delayed post-test.

\section{Instruments}

Three instruments were used in this study: vocabulary tests (pretest, post-test, delayed post-test), student questionnaire and semi-structured interview. The tests elicited impacts of the implementation of the mobile application based on constructivism on EFL students vocabulary learning. The vocabulary tests used in this study was designed according to Laufer's (1998) distinction about English words and Du's (2013) vocabulary test. There are 25 items in each test which includes three parts: matching the words with the corresponding definitions, filling in the blank with the given letters and choosing the correct answer from multiple choices. 25 words are selected randomly from all the core vocabulary in the textbook of English III for each test. The validity and reliability of these vocabulary tests are qualified.

The questionnaire and interview were used to obtain students' opinions and perceptions towards employing the mobile application to improve their vocabulary learning abilities. They were conducted in the following week after finishing all the experiment. The questionnaire in this study was designed according to Du (2013). The questionnaire contains 20 items which were written in both English and Thai In order to avoid misunderstanding. A Likert's scale was used which has five scales ranged from "strongly disagree" to "strongly agree". Also, a semi-structured interview included 8 items was employed in the current study to get the further information about opinions on using the application to learn vocabulary beyond classroom.

\section{Findings}

Data from different instruments will be used and presented to clearly and comprehensively illustrate the findings. 


\section{The effects of using the mobile application on vocabulary learning}

The effects of employing the constructivism-based mobile application on vocabulary learning were measured by the vocabulary pretest, post-test and delayed post-test. The findings were shown in Table 1 below.

Table 1: A Comparison between the Two Tests Scores between the Experimental Group and the Control Group

\begin{tabular}{lcccccc}
\hline Group & Tests & Mean & S. D. & $\mathrm{N}$ & $\mathrm{t}$ & Sig. \\
\hline \multirow{2}{*}{${ }^{*} \mathrm{EG}$} & Pretest & 16.00 & 3.528 & 10 & \multirow{2}{*}{-7.489} & \multirow{2}{*}{.009} \\
\cline { 2 - 5 } & Post-test & 23.10 & 0.738 & 10 & & \\
\hline \multirow{2}{*}{ CG } & Pretest & 15.90 & 4.280 & 10 & \multirow{2}{*}{-5.257} & \multirow{2}{*}{.009} \\
\cline { 2 - 5 } & Post-test & 21.50 & 1.509 & 10 & & \\
\hline
\end{tabular}

* EG: Experimental Group; *CG: Control Group

As shown in Table 1, from the Descriptive Analysis and Paired Samples T Test analysis, the mean scores of the post-test between the control group and the experimental group were 21.50 and 23.10 , respectively. In the experimental group, there was a statistically significant difference between the two tests scores because the $p$ value was 0.009 which was lower than 0.05. And the mean score of the post-test (23.10) was higher than that of the pretest (16.00). Also, in the control group, there was significant difference between the pretest and post-test scores because the $p$ value was lower than $0.05(p=0.009<0.05)$ and the mean scores of the pretest and the post-test were obviously different (15.90/21.50). It signifies that students in the two groups noticeably improved on their vocabulary learning.

\section{Table 2: Comparison between the Post-test Scores between the Experimental Group and the Control Group}

\begin{tabular}{lllllll}
\hline Group & Tests & Mean & SD & N & t & Sig. \\
\hline${ }^{*}$ EG & Post-test & 23.10 & 0.738 & 10 & \multirow{2}{*}{4.850} & \multirow{2}{*}{041} \\
\hline${ }^{*}$ CG & Post-test & 21.50 & 1.509 & 10 & & \\
\hline
\end{tabular}

Note:* EG: Experimental Group; *CG: Control Group

Furthermore, from the Independent Samples $T$ Test of the vocabulary post-test scores between the experimental group and the control group, as seen in Table 2, there was a statistically significant difference between the two scores, and the post-test mean scores of the experimental group (23.10) was much higher than that of the control group (21.50). It specifies that students in the experimental group achieved an improvement on their EFL vocabulary learning after employing the constructivism-based mobile application.

Additionally, the data from the vocabulary delayed post-tests were employed to test whether there was a significant difference between both groups in terms of their vocabulary retention. As seen in Table 3 below. 
Table 3: Comparison of the Delayed Post-test Scores between the Experimental Group and the Control group

\begin{tabular}{lllllll}
\hline Group & Tests & Mean & SD & $\mathrm{N}$ & $\mathrm{t}$ & Sig. \\
\hline${ }^{*} \mathrm{EG}$ & Delayed Post-test & 19.30 & 1.636 & 10 & \multirow{2}{*}{6.094} & \multirow{2}{*}{024} \\
\hline${ }^{*} \mathrm{CG}$ & Delayed Post-test & 15.70 & 3.974 & 10 & & \\
\hline
\end{tabular}

Note:* EG: Experimental Group; *CG: Control Group

As shows in Table 3, the data suggest that there is an obviously significant difference between the two groups because the $p$ value was 0.024 . It can be concluded that students in the experimental group store the vocabulary in long-term memory better than students in the control group. This result validates that the constructivism-based vocabulary learning mobile application has a positive effect on learners' vocabulary knowledge retention.

Overall, the data analysis indicates that effects after the implementation of constructivism-based vocabulary learning mobile application were as positive as expected, as evidenced by the fact that the scores in vocabulary post-tests improved and there was a highly significant difference between the two tests. Moreover, the data analysis from the vocabulary delayed post-tests indicated that the mobile application can be an effective tool on improving students' vocabulary retention. Therefore, the above results indicate that the mobile application can improve EFL learners' vocabulary learning successfully.

\section{Students' opinions towards utilizing the mobile application on improving their vocabulary learning}

As shown in Table 4 below, most of the participants delivered supportive opinions towards the implementation of the constructivism-based vocabulary learning application in EFL vocabulary learning. All of the students reported that the application is easy to use for vocabulary learning, and it can help them preview and review target words well. Furthermore, it is effective for learner to store the words in long-term retention. Moreover, $90 \%$ of them agreed that learning vocabulary via the application is convenient because they can learn and memorize words anytime and anywhere. Additionally, $90 \%$ of the students expressed that they enjoyed using the mobile application to learn vocabulary more than the vocabulary learning method they used in the past and the application motivates them to learn more new words. $90 \%$ of the students reported that they are able to construct the word meaning based on the context clues provided in the sentence by the application and used their prior knowledge. Also, there were $90 \%$ of them believed that the pictures provided by the application help them understand the sentences and guess the word meaning easily, especially for the abstract words, they can understand the target word meaning better. 
Table4. Responses from Student Questionnaires on the Likert-scale $(\mathrm{N}=10)$

\begin{tabular}{|c|c|c|c|}
\hline Items & $\begin{array}{l}\text { Agree } \\
(3 \\
\text { point) }\end{array}$ & $\begin{array}{l}\text { Not Sure } \\
\text { (2 point) }\end{array}$ & $\begin{array}{l}\text { Disagree } \\
\text { (1 point) }\end{array}$ \\
\hline & $\%$ & $\%$ & $\%$ \\
\hline $\begin{array}{l}\text { 1.The vocabulary learning application helps me remember } \\
\text { target words. }\end{array}$ & 100 & 0 & 0 \\
\hline 2. The vocabulary learning application is easy to use. & 100 & 0 & 0 \\
\hline $\begin{array}{l}\text { 3. Learning vocabulary via the application is convenient } \\
\text { since I can choose the place and time to learn new words. }\end{array}$ & 90 & 10 & 0 \\
\hline $\begin{array}{l}\text { 4. Learning vocabulary via the mobile application is } \\
\text { attractive. }\end{array}$ & 90 & 10 & 0 \\
\hline $\begin{array}{l}\text { 5. I enjoyed using the application to learn vocabulary more } \\
\text { than the method I used in the past. }\end{array}$ & 90 & 10 & 0 \\
\hline $\begin{array}{l}\text { 6. The vocabulary learning application motivates me to } \\
\text { learn new words. }\end{array}$ & 90 & 10 & 0 \\
\hline $\begin{array}{l}\text { 7. The vocabulary learning application is not useful for me } \\
\text { to learn new words. }\end{array}$ & 0 & 10 & 90 \\
\hline $\begin{array}{l}\text { 8. The contents on the application fit well with what I am } \\
\text { studying in class. }\end{array}$ & 90 & 10 & 0 \\
\hline $\begin{array}{l}\text { 9. The immediate feedback provided by the application } \\
\text { helps me monitor my vocabulary learning. }\end{array}$ & 90 & 10 & 0 \\
\hline 10. The preview part helps me prepare for the class well. & 90 & 10 & 0 \\
\hline $\begin{array}{l}\text { 11. The Review } 1 \text { part enables me to revise the } \\
\text { vocabulary knowledge. }\end{array}$ & 80 & 20 & 0 \\
\hline $\begin{array}{l}\text { 12. The reviewing exercises help me apply what l've } \\
\text { learned to the new contexts. }\end{array}$ & 90 & 10 & 0 \\
\hline $\begin{array}{l}\text { 13. The application enables me to extend my vocabulary } \\
\text { learning out of classroom. }\end{array}$ & 100 & 0 & 0 \\
\hline $\begin{array}{l}\text { 14. I guess the target word meaning based on the clues } \\
\text { provided in the sentence by the application and my } \\
\text { background knowledge. }\end{array}$ & 90 & 10 & 0 \\
\hline $\begin{array}{l}\text { 15. The pictures provided by the application help me } \\
\text { understand the sentences and guess the word meaning. }\end{array}$ & 90 & 10 & 0 \\
\hline $\begin{array}{l}\text { 16. Using the target words in new contexts helps me } \\
\text { consolidate word knowledge. }\end{array}$ & 90 & 10 & 0 \\
\hline $\begin{array}{l}\text { 17. The word knowledge gained by myself is not easily } \\
\text { forgotten. }\end{array}$ & 100 & 0 & 0 \\
\hline $\begin{array}{l}\text { 18. Using the target words in new contexts increases my } \\
\text { awareness of the word usage. }\end{array}$ & 90 & 10 & 0 \\
\hline $\begin{array}{l}\text { 19. The contexts provided by the application help me learn } \\
\text { how to use the target words correctly. }\end{array}$ & 100 & 0 & 0 \\
\hline $\begin{array}{l}\text { 20. The Review } 2 \text { provided by the application is effective } \\
\text { for me to store the words in long-term memory. }\end{array}$ & 90 & 10 & 0 \\
\hline
\end{tabular}

Moreover, the results from the students' interview indicate that most of the interviewees believed the constructivism-based mobile application has positive effect on improving their vocabulary learning. Some of the interviewees' opinions were as follows:

S1: "I like learning vocabulary by the application because it is convenient for me to learn and memorize words anytime and anywhere that I want. It is easy to use and helps me understand and remember the word meaning easily." (Translated)

S5: "I like the mobile application because it can improve my vocabulary knowledge. It helps me learn and remember the words." 
S6: "I enjoy learning vocabulary by the application because it is interesting to learn the words by the application and helps me remember the words. The pictures and example sentences are helpful for me to remember the word. It also helps me guess the word meaning easily."

In conclusion, both the quantitative and qualitative data from the case study confirm the effectiveness of utilizing the constructivism-based mobile application on improving learners' vocabulary learning.

\section{Discussion}

On the basis of the above mentioned comparative analysis between the experimental group and the controlled group, we can find that the constructivism-based mobile application does have certain influence on students' vocabulary learning, especially on their vocabulary knowledge and retention. There is clearly significant difference between the two groups about their vocabulary knowledge and retention; the scores of the tests demonstrate the effect of employing the mobile application in helping learners improve their vocabulary learning. Students' opinions also support the results. Mobile learning environment provide the advantages that constructing word knowledge with related pictures, sounds, example sentences, comprehensive contexts and individual learning. Learners can link their prior knowledge with the meaningful contexts to generate the word meaning independently.

The portability and convenience of the mobile application play a crucial important role in improving learners' vocabulary learning. Learners can learn and review the vocabulary with the mobile application in classes or out of the classroom at any times they wanted. The finding corroborates Steel's (2012) finding that mobile applications can be downloaded to their mobile devices and used productively anywhere at available time. Mobile application for language learning is a more practical help because it extends language learning outside of the classroom time, especially where the in-class language practice time is limited, and is essential to language acquisition (Steel, 2012). In summary, as Ting (2005) stated, the overall advantages provided by the mobile learning are more flexible, accessible and personalized learning activities. It motivates the learners engaged in the ongoing learning activities and enhances their productivity and effectiveness.

Constructivism theory also affects learners' vocabulary learning improvement. Learners linked their prior knowledge with the multiple contexts around the word to generate the meaning independently which is helpful for learners to construct the target words knowledge easily and store the words in long-term retention. As Poirer and Fledman (2007) stated, students are able to store vocabulary in long-term retention when they actively construct their own understanding of word knowledge through interacting with their prior knowledge and new information. Moreover, scaffolding is an effective learning support to provide comprehensible input to EFL learners so that they will actively build the vocabulary knowledge by using the mobile application. Vocabulary learning based on constructivism can help engage students to actively construct the vocabulary knowledge and increase their intrinsic motivation (DeVries \& Kohlberg, 1990).

The teacher's assistance and monitoring are very helpful in learners' vocabulary learning 
process. The students were able to finish the preview and review tasks in the application on time because the students' scores obtained from these tasks were recorded by the system and these data were sent to the teacher's e-mail. The teacher can know the students' vocabulary achievement and the total time spent on the vocabulary learning. Then, the teacher picked out the target words students commonly made mistakes and provided some related exercises for them to consolidate the vocabulary knowledge. Therefore, the results of this study revealed that after the students received the monitor and feedback from the teacher, there was a noticeable improvement in vocabulary knowledge. Similar finding was revealed in Simpson's research (2011) that teacher feedback not only enhanced student achievement in English language skills, but also maintained their enthusiasm for learning.

\section{Pedagogical implications and suggestions for further research}

The findings of the present study suggest that the vocabulary learning mobile application based on constructivism is effective for EFL learners' vocabulary knowledge and retention. The integration of MALL and constructivism is essential to the success of improving EFL learners' vocabulary learning in Thai context. The findings are directly beneficial to other researchers or teachers aiming at developing EFL students' vocabulary knowledge and retention. It also identifies a newer and more effective methodology for EFL vocabulary learning in Thailand.

Future study may expand the experimental time with more participants learning more target words. Learning other language skills via the mobile phone based on constructivism theory, may be a new investigation direction for future research. Equally important is the improvement of the mobile application. Further studies should improve the constructivism-based vocabulary learning mobile application in terms of the network connection.

\section{References}

Alemi, M., Sarab, M. R. A., \& Lari, Z. (2012). Successful learning of academic word list via MALL: Mobile assisted language learning. International Education Studies, 5(6), 99.

Basoglu, E. B., \& Akdemir, O. (2010). A comparison of undergraduate students' English vocabulary learning: Using mobile phones and flash cards. Turkish Online Journal of Educational Technology-TOJET, 9(3), 1-7.

Boonkongsaen, N. (2013). Factors affecting vocabulary learning strategies: A synthesized study. Naresuan University Journal: Science and Technology, 20(2), 45-53.

Chen, N. S., Hsieh, S. W., \& Kinshuk, A. (2008). Effects of short-term memory and content representation type on mobile language learning. Language learning \& technology, 12(3), 93-113.

Daloğlu, A., Baturay, M. \& Yildirim, S. (2009). Designing a constructivist vocabulary learning material. In R, C. V. Marriott \& P, L. Torres (Eds.), Handbook of research on E-learning methodologies for language acquisition (pp. 186-203). Hershey, PA: Information Science.

DeVries, R., \& Kohlberg, L. (1990). Constructivist early education: Overview and comparison with other programs. Washington, DC: National Association for the Education of Young Children. 
Du, X. H. (2013). An empirical study on multimedia-based social constructivist model in English vocabulary acquisition. Journal of Language Teaching and Research, 4(5), 1036-1043.

Hayati, A., Jalilifar, A., \& Mashhadi, A. (2013). Using Short Message Service (SMS) to

teach English idioms to EFL students. British Journal of Educational

Technology, 44(1), 66-81.

Laufer, B., \& Paribakht, T. S. (1998). The relationship between passive and active vocabularies: Effects of language learning context. Language Learning, 48(3), 365-391.

Lin, Y. Y. (2015). The Acquisition of Words' Meaning Based on Constructivism. Theory and Practice in Language Studies 5(3), 639-645.

Mackey, D., \& Savage, A. (2010). Read This! Level 2 Student's Book: Fascinating Stories from the Content Areas. Cambridge: Cambridge University Press.

Nirattisai, S., \& Chiramanee, T. (2014). Vocabulary learning strategies of Thai university students and its relationship to vocabulary size. International Journal of English Language Education,2(1), 273.

Poirier, C. R., \& Feldman, R. S. (2007). Promoting active learning using individual response technology in large introductory psychology classes. Teaching of Psychology, 34(3), 194-196.

Rahimi, M., \& Miri, S, S. (2014). The impact of mobile dictionary use on language learning. Procedia Social and Behavioral Sciences, 98,1469-1474.

Sawangwaroros, B. O. (1984). American and British English. Phasa Parithat Journal, 4(2), 24-37.

Simpson, J. (2011). Integrating project-based learning in an English language tourism classroom in a Thai University (doctoral dissertation). Australian Catholic University, North Sydney, Australia.

Squire, K., \& Dikkers, S. (2012). Amplifications of learning: Use of mobile media devices among youth. Convergence: The International Journal of Research into New Media Technologies, 18, 445-464.

Steel, C. (2012). Fitting learning into life: Language students' perspectives on benefits of using mobile apps. Ascilite, 875-880.

Sukkong, J. (2010). Learning achievement, retention, and attitudes towards English vocabulary learning of students taught games and conventional method (Unpublished master's thesis). Prince of Songkla University, Kathu, Thailand.

Thornton, P., \& Houser, C. (2005). Using mobile phones in English education in Japan. Journal of Computer Assisted Learning, 21, 217-228.

Ting, Y. R. (2005). Mobile Learning: Current Trend and future Challenges. Proceedings of the Fifth International Conference on Advanced Learning Technologies, Los Alamitos, CA: IEEE Computer Society Press. 
Ward, J. (2000). SUT Students' Proficiency in Reading Subject-Specific Textbooks in English. Institute of Social Technology, Suranaree University of Technology, Nakhon Ratchasima, Thailand. 